\title{
Leishman-Donovan (LD) bodies in bone marrow biopsy of an adult male with AIDS
}

\section{AIDS hastası yetişkin erkeğin kemik iliği biyopsisinde Leishmania Donovan (LD) cisimciği}

\author{
Abbas Hashim Abdulsalam1, Fatin Al-Yassin ${ }^{2}$ \\ ${ }^{1}$ Hematology Unit, Lab Department, Al-Yarmouk Teaching Hospital, Baghdad, Iraq \\ 2Department of Hematology, Teaching Laboratories, Medical City, Baghdad, Iraq
}

We report the case of Leishman-Donovan (LD) bodies in the bone marrow biopsy of an Iraqi adult male with acquired immunodeficiency syndrome (AIDS). The patient was working in a United States military camp in Baghdad, Iraq. He was diagnosed as having human immunodeficiency virus (HIV) infection within only a few days of diagnosis of visceral leishmaniasis (kala-azar). Visceral leishmani-

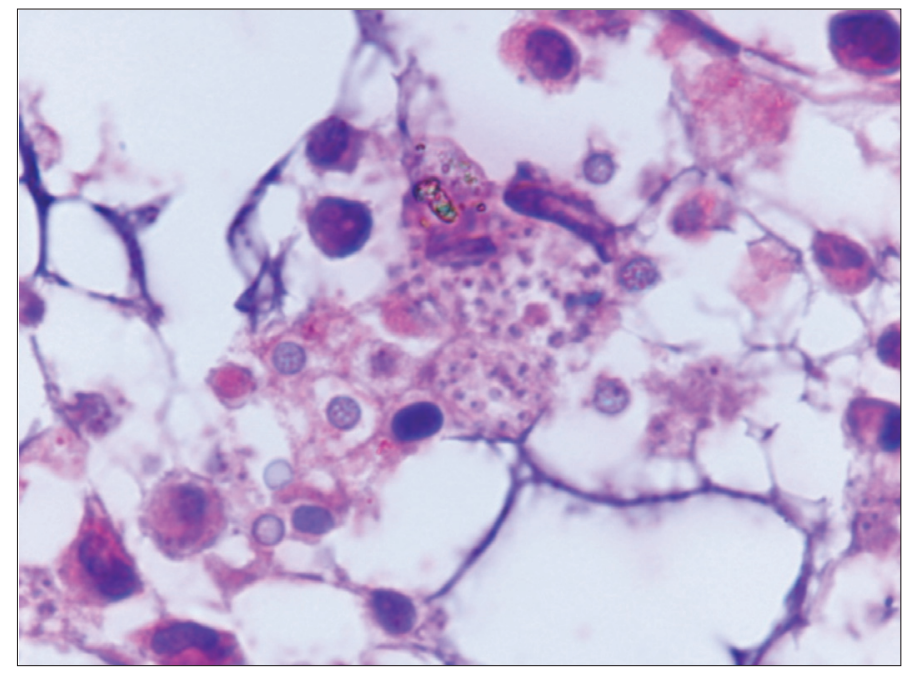

Figure 1. Bone marrow trephine biopsy, H\&E stain X100, parrafin embedded: Patient with AIDS and Visceral leishmaniasis. asis is one of the opportunistic infections in AIDS patients.

The interesting point of this case is that the finding of $\mathrm{LD}$ bodies in the bone marrow biopsy is rare.

In this case, the bone marrow aspirate was diluted, and this caused us to miss the diagnosis of visceral leishmaniasis. However, when we examined the biopsy slides, the diagnosis was clear. A

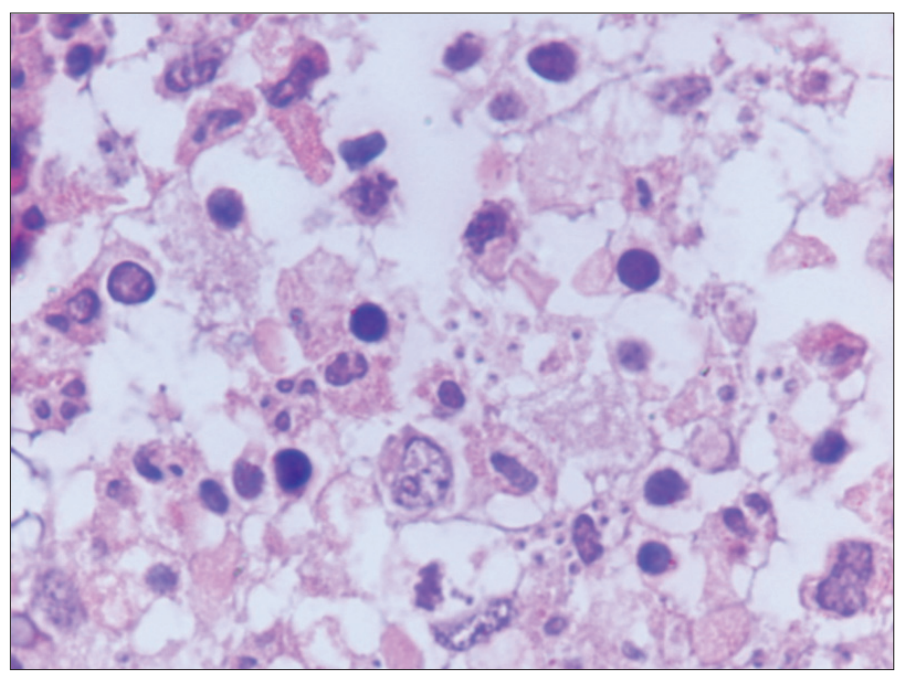

Figure 2. Bone marrow trephine biopsy, H\&E stain X100, parrafin embedded: Many Leishman-Donovan bodies seen. 


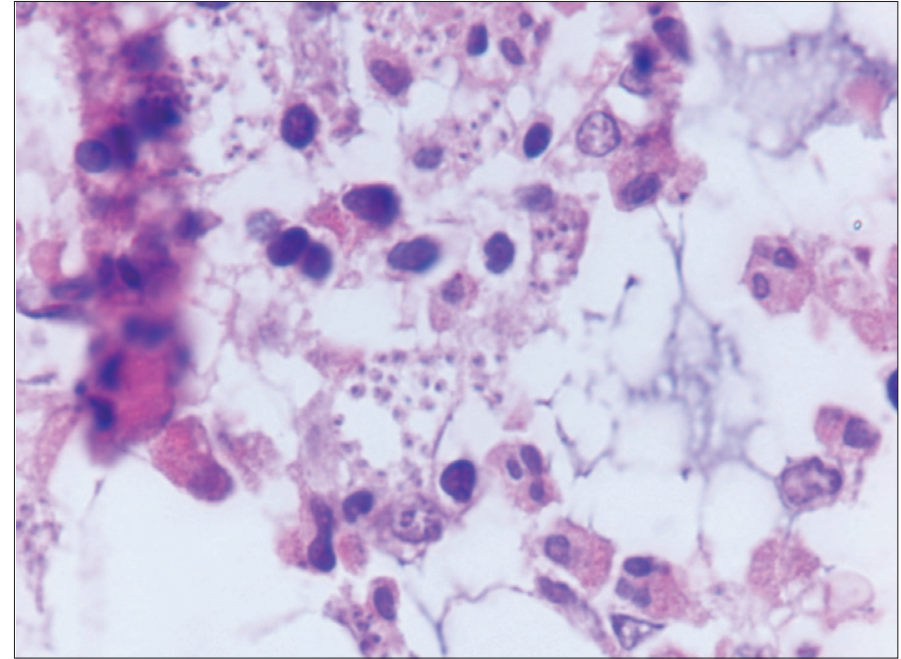

Figure 3. Bone marrow trephine biopsy, H\&E stain X100, parrafin embedded: Leishman-Donovan bodies, nucleus and paranuclear kinetoplast seen, few are with the typical "double-dot" appearance.

retrospective reexamination of the aspirate slides revealed only a few LD bodies.

\section{Acknowledgement}

Informed consent was obtained from the patient.

\section{Conflict of Interest}

No author of this paper has a conflict of interest,

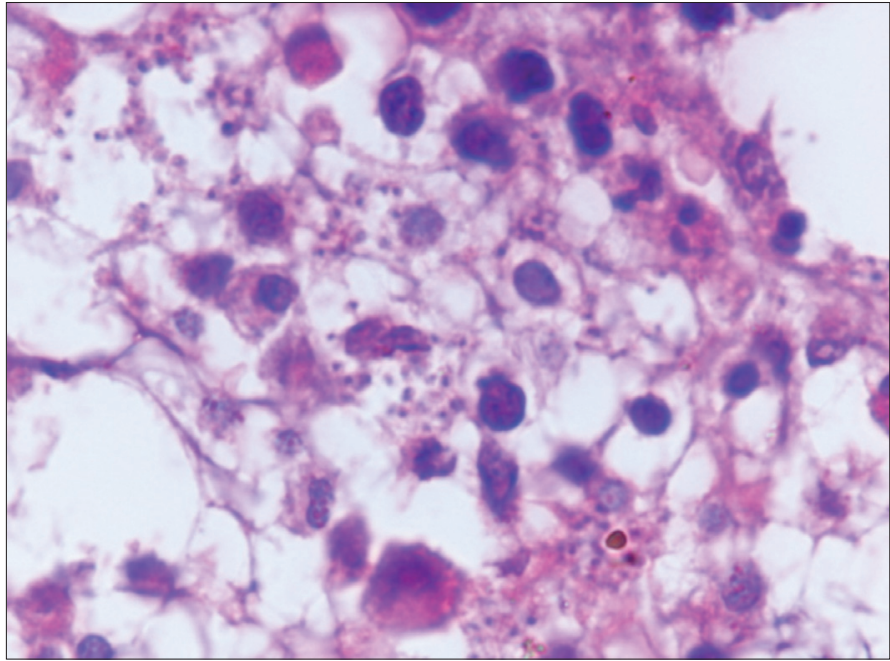

Figure 4. Bone marrow trephine biopsy, H\&E stain X100, parrafin embedded: The tissue form of the protozoal pathogen producing Visceral leishmaniasis is the Leishman-Donovan body which is an intracellular amastigote.

including specific financial interests, relationships, and/or affiliations relevant to the subject matter or materials included in this manuscript.

\section{References}

1. Hoffbrand AV, Pettit JE. Color Atlas of Clinical Hematology. 3rd ed. St. Louis: Mosby, 2006. 